\title{
The impact of new firm formation on regional development in the Netherlands
}

\author{
André van Stel · Kashifa Suddle
}

Received: 4 November 2005/Accepted: 20 March 2007 / Published online: 19 June 2007

(C) Springer Science+Business Media B.V. 2007

\begin{abstract}
This paper examines the relationship between new firm formation and regional employment change in The Netherlands. Using a new regional data base for the period 1988-2002, we examine the time lags involved in the relationship. We also investigate whether the relationship differs by sector and by degree of urbanization. We find that the maximum effect of new businesses on regional development is reached after about 6 years. Our results also suggest that the overall employment impact of new-firm start-ups is positive but that the immediate employment effects may be small in The Netherlands. Furthermore, we find that the employment impact of new firms is strongest in manufacturing industries and that the employment impact of new firms is stronger in areas with a higher degree of urbanization.
\end{abstract}

Keywords Start-ups $\cdot$ Entrepreneurship $\cdot$ Regional development . The Netherlands

\section{JEL-codes $\quad \mathrm{J} 23 \cdot \mathrm{L} 10 \cdot \mathrm{L} 26 \cdot \mathrm{M} 13 \cdot \mathrm{R} 11$}

A. van Stel $(\bowtie) \cdot$ K. Suddle EIM Business and Policy Research, P.O. Box 7001, 2701 AA Zoetermeer, The Netherlands e-mail: ast@eim.nl

\section{A. van Stel}

Cranfield School of Management, Cranfield University, Bedford, UK

\section{Introduction}

It is frequently argued that in the last 30 years the innovative advantage has moved from large, established enterprises to small and new firms, because new technologies have reduced the importance of scale economies in many sectors (e.g. Meijaard 2001). Also, an increasing degree of uncertainty in the world economy from the 1970s onwards has created more room for innovative entry (Audretsch and Thurik 2001). A consequence of these developments is that the importance of new and small firms for economic development has increased. Since the seminal work of Birch (1987), who stated that small and medium-sized enterprises create most of the new jobs, the interest in entrepreneurship and SMEs in relation to job creation has grown rapidly. Many studies have shown that SMEs do play an important role in job creation (e.g. Broersma and Gautier 1997; Picot and Dupuy 1998). Others state that this role is overestimated due to the high-job destruction rate among SMEs (e.g. Davis et al. 1996). De Kok et al. (2006) show that small and medium-sized firms can be seen as the main source of employment growth in The Netherlands during the period 1993-1998. ${ }^{1}$ Roughly two/third of net annual employment growth

\footnotetext{
${ }^{1}$ In de Kok et al. (2006) small firms are defined as firms with a work force of 0-9 full-time equivalents. Medium-sized firms have a work force of 10-99 and large firms have a work force of 100 and more full-time equivalents.
} 
can be attributed to small and medium-sized firms. In addition, the average annual net employment creation rate is $2.4 \%$ for small firms, $1.2 \%$ for medium-sized firms and $0.7 \%$ for large firms during the period mentioned. Verhoeven et al. (2005) report that in The Netherlands, $30 \%$ of total gross job creation in 2004 was accounted for by new-firm start-ups. These studies mark the important contribution of new and small firms to economic development in modern economies.

The relationship between new firm formation and economic development is complex. When new businesses enter a market, they may have both direct and indirect effects on the economic performance of the market they enter. The direct or immediate effect relates to the new jobs that are created in the new units at the start of business operations. The indirect effects occur some time after the new firms have started and relate to the crowding-out of competitors (negative effect) and, still later, to improved competitiveness of the industry induced by the increased competition of the new firms (Fritsch and Mueller 2004).

The present paper investigates the time lags related to the direct and indirect effects of new businesses on the economic performance of the market they enter. In particular, using a data base for 40 regions in The Netherlands over the period 1988-2002, we examine the lag structure of the impact of new firms on employment change. When investigating the relation between new firm formation and economic development we realize that, besides the lag structure, at least two other aspects are of importance. First, the relation may differ by sector of economic activity. It is generally well-known that start-ups in manufacturing are quite different from start-ups in services, for instance in terms of the amount of start-up capital required. Furthermore, the quality of start-up projects may differ between sectors (selection effect). Hence the impact of new firm formation on employment may differ as well. Second, the degree of urbanization may influence the relation as well. In areas where business density is higher, agglomeration advantages and knowledge spillovers may also be higher, and hence the economic impact of new firms may be higher. Again, the quality of start-up projects may differ between rural and urban areas (selection effect), for instance because highly skilled individuals move to the cities in order to find employment. In this paper, we also examine whether the relation between new businesses and regional development differs by sector and by degree of urbanization.

We find that the maximum effect of new businesses on regional development is reached after about 6 years. Our results also suggest that the overall employment impact of new-firm start-ups is positive but that the immediate employment effects may be small in The Netherlands. Furthermore, we find that the employment impact of new firms is strongest in manufacturing and that the employment impact of new firms is stronger in areas with a higher degree of urbanization.

The organization of this paper is as follows. In Sect. 2, we discuss the theory and earlier empirical evidence for The Netherlands. Section 3 describes our data base on start-ups and employment for the Dutch regions while Sect. 4 deals with the model and methods that we use in our paper. In the last sections the results are presented and interpreted.

\section{Theory and earlier work}

\subsection{Theory}

As mentioned, when new businesses enter an industry, they may have both direct and indirect effects on industry-wide economic performance. The direct effect relates to the new jobs that are created in the new units at the start of business operations. The indirect effects relate to the effects the new businesses have on the incumbent firms in the market. There are several types of indirect effects, which may be negative or positive. For instance, one may think of job destruction in the least competitive incumbent firms through increased competition of the new firms (negative effect). On the other hand, there are also positive effects. Incumbents imitate innovations made by new firms. The incumbent firms are also stimulated to innovate themselves. Furthermore, to resist the threat of start-ups, incumbents lower their prices, which, in turn, increases demand for products and services (Verhoeven 2004). For a more elaborate discussion of the direct and indirect effects of new firm formation we refer to Fritsch (2007).

In this study, we will also investigate whether the relationship between business creation and employment growth differs by sector. One might argue that a 
higher start-up rate has more impact in sectors with a higher innovation-intensity compared to non-innovative sectors. More intense competition in innovative sectors may lead to a higher speed of technological progress, which in the longer run may lead to higher growth in these sectors.

As mentioned, we also investigate whether the degree of urbanization influences the relation between new firms and employment growth. When many firms are located close to each other in heavily populated areas, positive agglomeration effects may emerge, e.g. access to a broader labour market, the sharing of research organizations and the easier diffusion of (tacit) knowledge (Werker and Athreye 2004, p. 508). As knowledge spillovers tend to be localized, the new knowledge generated or induced by a given number of new firms spills over to potentially more applications in concentrated regions. Hence it may be expected that the economic impact of new firms increases with the degree of urbanization. Support for the existence of agglomeration advantages is provided by several studies that argue that knowledge spillovers are more pronounced in concentrated regions (Agrawal 2002; Autant-Bernard 2001; Caniëls 2000; Audretsch 1998).

The importance of agglomeration effects is also investigated by Brakman et al. (2005). They estimate econometric models derived from the New Economic Geography (Fujita et al. 1999, Fujita and Thisse 2002), using a data base for European regions. The New Economic Geography is a relatively new branch of economics that incorporates agglomeration advantages and location choice in a formal general equilibrium framework. Firms choose to locate in core regions or in peripheral regions. At the aggregate level, based on a trade-off between agglomeration advantages (e.g. lower trade costs because of a larger local market) and agglomeration disadvantages (e.g. congestion; high-land prices) a 'dispersion equilibrium' (supporting an even distribution of economic activity across regions), or an 'agglomeration equilibrium' (supporting a disproportionate amount of economic activity in core regions) may emerge. For their European data base Brakman et al. (2005) find empirical support for an 'agglomeration equilibrium' to exist. This implies that regional disparities are persistent. We will perform some exercises to investigate whether agglomeration effects exist within The Netherlands as well.

\subsection{Empirical evidence for the Netherlands}

Several empirical studies of the relation between start-up activity and economic performance have adopted different approaches yielding different results. For a discussion of these (international) results we refer to van Stel and Storey (2004) and Fritsch (2007). In this paper, we will limit ourselves to the empirical studies performed for The Netherlands.

Empirical investigations to the relation between the number of (new) businesses and economic performance at the regional level for The Netherlands are scarce. This is related to the limited use and availability of regional start-up data. As far as we know, original research using systematic information on the number of start-ups and the number of businesses in The Netherlands covering all economic activity is only performed at EIM Business and Policy Research. ${ }^{2}$ Hence the only Dutch studies on the topic are also EIMbased. Nevertheless the empirical evidence is mixed.

In EIM (1994, pp. 41-47), a principal component type of analysis is conducted, using data for Dutch COROP regions in the period $1987-1990 .{ }^{3}$ No relation is found between employment growth and the principal component 'firm dynamics' (determined by the numbers of entries and exits). Bosma and Nieuwenhuijsen (2002) investigate the impact of turbulence (sum of entries and exits) on growth of total factor productivity for Dutch COROP regions in the period 1988-1996. They find a positive effect for services and no effect for manufacturing. Van Stel and Nieuwenhuijsen (2004),

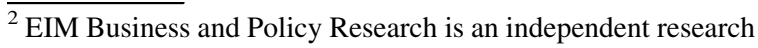
and consultancy organization based in The Netherlands with about 80 regular employees. EIM has been carrying out policy research on enterprise issues for 75 years in various fields such as entrepreneurship and business development, employment, ICT, innovation, internationalisation and administrative burdens. On behalf of the Dutch Ministry of Economic Affairs EIM carries out a large research programme on SMEs and entrepreneurship.

${ }^{3}$ The COROP classification is the regional classification for The Netherlands at the NUTS-III spatial aggregation level. The NUTS Boundaries data set (Nomenclature des Unites Territoriales Statistiques) shows sub-national administrative areas within the European Community (EC). Every EC member state has different levels of administrative subdivisions, designated as NUTS-I, NUTS-II and NUTS-III (these are the smallest regions). In The Netherlands the regions at NUTS-III level are also known as 'COROP' regions, named after the committee who designed the regional classification for The Netherlands in 1971.
} 
using the same regional data base, find an opposite result: a positive effect of the number of businesses on regional growth for manufacturing, and no effect for services. A number of differences between the studies may be responsible for these different findings. First, EIM (1994) and Bosma and Nieuwenhuijsen (2002) use a measure of firm dynamics (entry and exit) while van Stel and Nieuwenhuijsen (2004) use the total number of businesses as a measure of competition.

Second, while the former two studies scale their measures on the number of existing businesses, the latter uses regional employment as a scaling variable. The choice of scaling variable is not trivial. Given that the units of account are geographical areas that vary in size, the number of start-ups needs to be normalized by a size measure. The denominator should both control for the different absolute sizes of the regions concerned, and represent the source from which start-ups or firm formations are most likely to come (Ashcroft et al. 1991). The two most commonly used denominators are the stock of existing firms, and the size of the regional workforce (or the level of regional employment). These approaches are called the ecological approach and the labour market approach, respectively (Audretsch and Fritsch 1994). The ecological approach assumes new firms arise from existing ones, whereas the labour market approach assumes that new firms arise from (potential) workers. The choice of measure can be highly significant. For example, for a given number of startups, regions which are equally large in terms of workforce but which are different in terms of average firm size, will have the same start-up rate according to the labour market approach but different start-up rates according to the ecological approach. Garofoli (1994) makes a robust case in favour of 'labour market' over 'ecological'. The latter, he argues, is misleading in areas with small numbers of (generally large) firms. Here small numbers of new firms would provide an artificially high-birth rate, primarily because of the small values of the denominator. Audretsch and Fritsch (1994) demonstrate that, in West Germany, the statistical relationship between unemployment and start-up activity crucially depends on the ecological or labour market methods used to measure start-up rates. We favour the Garofoli arguments and, in line with van Stel and Nieuwenhuijsen (2004), in this paper we will use the labour market approach (see also Sect. 3).
A third reason for the different findings between the three studies may be the different control variables employed. In particular, van Stel and Nieuwenhuijsen (2004) control for spatial autocorrelation, while EIM (1994) and Bosma and Nieuwenhuijsen (2002) do not. Spatial autocorrelation refers to the phenomenon that regions are economically interdependent, which may cause the disturbance terms of neighbouring regions in a regression model to be correlated. The problem of spatial autocorrelation may emerge in particular when the regions are defined to be small, and when the dependent variable relates to economic performance (as is the case for the studies under consideration). Hence it is essential to correct for spatial autocorrelation in this type of studies.

Although it is difficult to establish exactly how the differences mentioned above are related to the different empirical results, it is likely that the differences in approach are part of the explanation for the different results found in these studies. In any case, the need for further research is clear. In particular, while the most recent data used in the studies mentioned above are for 1996, the present study will use data up to and including 2002.

\section{Data}

In this paper, we use a regional data base for the period 1988-2002. The regional aggregation level employed is the Dutch COROP level (spatial NUTSIII level), which consists of 40 regions. The data are also subdivided by sector. The sectoral classification contains five main sectors of the Dutch economy, viz. manufacturing (International Standard Industrial Classification code D), construction (ISIC code F), trade (ISIC codes GH), transport and communication (ISIC code I) and services (ISIC codes JKNOP). The definitions and sources of the main variables used in this study are given below. With the exception of population density the variables are available at the regional and sectoral level as described above.

- Employment growth. Data on employment are taken from Statistics Netherlands and the employment figures relate to employee jobs expressed in full-time equivalents or labour years. Part-time work is proportionally being counted as fulltime work. Self-employed workers and unpaid family 
workers are excluded from the data. The employment levels have been measured at the first of January each year. The employment growth rates are measured over periods of 3 years, and are expressed in per cent points.

- Start-up rate. Following the labour market approach we define the start-up rate as the number of new-firm start-ups divided by employment in full-time equivalents (as described above). The data on the number of start-ups are taken from the Dutch Chambers of Commerce. The number of start-ups is defined to include all independent new-firm registrations. It includes both new firms with employees and new firms without employees. Mergers, new subsidiary companies, new branches and relocations to other regions are not counted as a start-up.

- Wage growth measures three-yearly changes in regional wage rates and is expressed in per cent points. The wage rate is computed as total wages in a sector/region divided by the employment of employees in full-time equivalents. Data on wages are also taken from Statistics Netherlands (CBS). Because sectoral classifications used by CBS changed in 1993, corrections had to be made in order to arrive at wage rates according to a uniform sectoral classification.

- Data on population density were also taken from Statistics Netherlands.

Some descriptive statistics for the dependent variable in this study (3-year employment growth) and the main independent variable (the start-up rate) are presented below. The statistics are presented by time period (Table 1), by sector of economic activity (Table 2) and by major region (Table 3). Table 1 shows that in the period 1996-1999 employment growth was three times as high compared to the other periods, corresponding to the boom of the Dutch economy in this period. Average start-up rates are quite stable over time though. ${ }^{4}$ From Table 2 we see that in

\footnotetext{
4 An explanation may be that for those self-employed individuals who practise a 'free profession' (e.g. consultants, notaries, etc.) it is not compulsory to register their business at the Chamber of Commerce. As the economic upturn may have benefited this group of self-employed in particular, the increase in 'free profession' self-employed may not be fully reflected by the statistics. However, a more plausible explanation is that, besides the number of start-ups, the denominator of the start-up rate (i.e. the level of employment) has risen as well, yielding
}

Table 1 Mean and standard deviation of employment growth and start-up rate, by time period

\begin{tabular}{lrrrr}
\hline & $1990-$ & $1993-$ & $1996-$ & $1999-$ \\
& 1993 & 1996 & 1999 & 2002 \\
\hline $\begin{array}{l}\text { Employment growth } \\
\text { Mean }\end{array}$ & 3.08 & 3.25 & 9.27 & 3.63 \\
$\begin{array}{l}\text { Standard } \\
\text { deviation }\end{array}$ & 7.52 & 10.11 & 10.32 & 8.11 \\
$\begin{array}{c}\text { Start-up rate } \\
\text { Mean }\end{array}$ & 12.41 & 12.84 & 12.84 & 11.71 \\
$\begin{array}{c}\text { Standard } \\
\text { deviation }\end{array}$ & 8.78 & 7.94 & 7.58 & 6.96 \\
Number of & & & & \\
observations & 200 & 200 & 200 & 200 \\
\hline
\end{tabular}

Employment growth is measured over 3-year periods, and expressed in \%-points. Start-up rate is the number of start-ups per 1,000 labour years

the period 1990-2002 employment grew fastest in the services industries. We also see that manufacturing has the lowest start-up rate. This is caused by the higher entry barriers in this sector, for instance the level of start-up capital required to start a firm in this sector is much higher compared to the average new firm in the service or trade sectors. ${ }^{5}$ Table 3 , finally, shows that there are also differences by regions at the NUTS-I level, particularly in employment growth levels. Differences in the number of start-ups are not so high. Note however that these statistics are averaged both over time and over sectors, hence differences that exist at the sector level are not visible in Table 3.

\section{Model and research design}

As mentioned earlier, in investigating the impact of new firms on regional employment, we focus on the lag structure of the impact, and on differences between sectors and degree of urbanization, respectively. These

Footnote 4 continued

the start-up rate to be stable over time. Indeed, further investigation reveals that over the period 1991-2002 both the number of start-ups and employment in fulltime equivalents (FTEs) have increased with some $21.7 \%$ (on average $1.8 \%$ per year). However, in the booming years 1999 and 2000 the rises in the absolute number of start-ups were 9.6 and $16.3 \%$, respectively (for the whole Dutch economy).

5 Additionally, the shift of economic activity away from manufacturing and towards services, which takes place in almost all Western economies, causes the number of start-ups in manufacturing to be relatively low. 
Table 2 Mean and standard deviation of employment growth and start-up rate, by sector, 1990-2002

\begin{tabular}{|c|c|c|c|c|c|}
\hline & Manufacturing & Construction & Trade & Transport and communication & Services \\
\hline \multicolumn{6}{|l|}{ Employment growth } \\
\hline Mean & -3.62 & 2.58 & 6.33 & 3.75 & 11.50 \\
\hline Standard deviation & 6.75 & 10.22 & 5.55 & 11.06 & 7.13 \\
\hline \multicolumn{6}{|l|}{ Start-up rate } \\
\hline Mean & 3.30 & 17.19 & 19.29 & 8.56 & 16.01 \\
\hline Standard deviation & 1.68 & 6.49 & 6.93 & 4.79 & 4.85 \\
\hline Number of observations & 160 & 160 & 160 & 160 & 160 \\
\hline
\end{tabular}

Employment growth is measured over 3-year periods, and expressed in \%-points. Start-up rate is the number of start-ups per 1,000 labour years

Table 3 Mean and standard deviation of employment growth and start-up rate, by major region, 1990-2002

\begin{tabular}{lrrrr}
\hline & North & East & West & South \\
\hline Employment growth & & & & \\
$\quad$ Mean & 4.66 & 5.46 & 2.80 & 4.85 \\
$\quad$ Standard deviation & 11.21 & 9.22 & 9.10 & 9.43 \\
Start-up rate & & & & \\
$\quad$ Mean & 13.75 & 12.79 & 12.97 & 11.60 \\
$\quad$ Standard deviation & 8.31 & 8.80 & 7.57 & 7.44 \\
Number of observations & 180 & 160 & 320 & 140 \\
\hline
\end{tabular}

Employment growth is measured over 3-year periods, and expressed in \%-points. Start-up rate is the number of start-ups per 1,000 labour years

different angles of looking at the relationship call for different model specifications and research designs to be used. In particular, in terms of panel data analysis, the model focusing on the lag structure calls for a within-type of analysis (investigating the impact of changes in the start-up rate over time) while the other types of analyses call for a between-type of analysis (investigating differences in the start-up rate between regions). The research design that we will use in each case will be described below.

\subsection{Research design for analysis of the lag structure of the economic impact of new firms}

\subsubsection{Sector adjustment in data}

In this analysis, we focus on the start-up rate for the whole regional economy. Therefore for each region the sectoral data have to be aggregated to the regional economy level. In doing so we use the sector adjusted start-up rate. The start-up rates are sectorally adjusted to correct for different sector structures across regions. Differences in sector structures lead to different start-up rates at the aggregate level, because start-up rates are far from identical across sectors (see Table 2). The regional sector start-up rates are weighted by employment by sector for The Netherlands as a whole (see Ashcroft et al. 1991). Hence we impose an identical sector structure on each region. In this way, we eliminate the impact of sector structure from our analysis. Similarly, we also apply a sector adjustment (using the same weighting scheme) for the variables employment growth and wage growth.

\subsubsection{Almon lags}

As we are interested in the short-, medium- and longrun impact of new firms on regional employment growth, we would, in principle, want to estimate a regression where employment change is explained by the sector adjusted start-up rate and several lags of the start-up rate. However, in reality regional start-up rates are heavily correlated over time (see Table 4) causing severe problems of multicollinearity. To avoid these problems we use the Almon lag method. Basically this method imposes restrictions on the parameters of the start-up rates in such a way that the estimated coefficients of the start-up rates are a function of the lag length. By substituting these restrictions back in the original equation one arrives at a more compact model, which can be estimated without problems of multicollinearity. We refer to Stewart (1991, pp. 180-182) for a general description of the Almon method and to van Stel and Storey (2004, pp. 905-907, Appendix 3) for a similar application of this method using start-up rates and employment growth rates of British regions. 
Table 4 Correlations over time of sector adjusted start-up rates $(S), N=280$

\begin{tabular}{llllllllll}
\hline & $S_{t}$ & $S_{t-1}$ & $S_{t-2}$ & $S_{t-3}$ & $S_{t-4}$ & $S_{t-5}$ & $S_{t-6}$ & $S_{t-7}$ & $S_{t-8}$ \\
\hline$S_{t}$ & 1 & & & & & & & & \\
$S_{t-1}$ & 0.89 & 1 & & & & & & & \\
$S_{t-2}$ & 0.81 & 0.90 & 1 & & & & & & \\
$S_{t-3}$ & 0.77 & 0.82 & 0.90 & 1 & & & & \\
$S_{t-4}$ & 0.70 & 0.73 & 0.79 & 0.90 & 1 & & & \\
$S_{t-5}$ & 0.65 & 0.65 & 0.69 & 0.78 & 0.90 & 1 & & \\
$S_{t-6}$ & 0.59 & 0.59 & 0.59 & 0.67 & 0.78 & 0.89 & 1 & & \\
$S_{t-7}$ & 0.54 & 0.57 & 0.56 & 0.58 & 0.68 & 0.78 & 0.89 & 1 \\
$S_{t-8}$ & 0.49 & 0.54 & 0.55 & 0.52 & 0.58 & 0.69 & 0.77 & 0.88 & 1 \\
\hline
\end{tabular}

\subsubsection{Control variables}

When estimating our Almon lag model where the impact of the start-up rate on the 3-year employment growth rate is estimated as a function of the lag of the start-up rate, we include some control variables, which are also expected to influence regional employment change. First, we correct for spatial autocorrelation, i.e. the phenomenon that regions are economically interdependent, causing the growth rates and disturbance terms of neighbouring regions to be correlated. To correct for this, following Fritsch and Mueller (2004), we compute for each region the average of the residuals in the neighbouring regions and include this variable as an explanatory variable in the model. Second, following van Stel and Storey (2004) we also include wage growth as an explanatory variable. In labour economics local wage growth is a common determinant of employment growth. Rees and Shah (1986) assume a welfare maximizing individual chooses between utility in self-employment compared with paid employment, for which wages are taken as the proxy. Hence rises in wage rates would be expected to lead to movements into wage-employment and out of self-employment, consistent with a positive effect on employment change (which in the present study is defined to include employees only). Furthermore, higher wages may indicate rising demand implying regional growth. However, there is also a negative effect as a higher price of labour may lead to a lower demand for labour (substitution between capital and labour). These opposite effects make the sign of wage rates indeterminate from theory.

\subsubsection{Estimation method}

As the focus of this analysis is on the effects of new firms over time, we will make use of fixed effects estimation. For each region only the deviations from the average over time of the model variables are considered. Basically the unobservable-time invariant structural differences between regions are eliminated in this way. Furthermore, to safeguard a straightforward interpretation of the regression results, we remove outlier observations. ${ }^{6}$

\subsection{Research design for analyses of sectors and degree of urbanization}

For our analyses by sector and by degree of urbanization we do not need to make use of aggregate start-up rates at the whole regional economy level. We directly use the data at the regional and sectoral level. Furthermore, because the focus here is on the differences between regions we will not include startup rates from every period. Instead we use the average start-up rate for the 3 years immediately preceding the period over which the dependent variable employment growth is calculated.

\subsubsection{Control variables}

Besides the controls for spatial autocorrelation and wage growth described in Sect. 4.1, we include two

\footnotetext{
${ }^{6}$ Those observations, which have an absolute normalized residual greater than 2.5 are removed (on average some $3 \%$ of the original sample observations).
} 
further control variables here. The first control factor is population density. This variable may capture several effects. According to Audretsch and Fritsch (2002, p. 120), who also use population density as a control in their regressions for Germany, 'population density here represents all kinds of regional influences such as availability of qualified labour, house prices, local demand and the level of knowledge spillovers'. The second additional control factor is lagged employment growth. Those regions with higheconomic growth may be attractive areas for new firms to locate as local demand is high. This reversed causality effect potentially causes the impact of startup rates on employment growth to be overestimated. This is due to positive path dependency in the economic performance of regions (i.e. the business cycle effect). We correct for this by including a lagged dependent variable. ${ }^{7}$ Note that both these control variables relate to the differences between regions hence we do not include them in the fixed effects analysis described in Sect. 4.1. Furthermore, for the analysis of the degree of urbanization, we correct for sectoral differences by including sectoral dummies. As we are primarily interested in crossregional differences here, we do not make use of fixed effects estimations. Instead we simply use OLS. Again outlier observations are removed.

\subsubsection{Degree of urbanization}

As mentioned we also investigate whether the relation between new firms and regional growth is dependent on the degree of urbanization. For this purpose, we create interaction terms of the start-up rate multiplied by a variable measuring a region's degree of urbanization or degree of rurality. These latter variables are taken from Statistics Netherlands (CBS). In particular, for each COROP region CBS provides figures on the percentages of land that can be classified as 'very urbanized', 'urbanized', 'moderately urbanized', 'slightly urbanized' and 'not urbanized'. The classes 'very urbanized' and 'urbanized' together form an indicator for the degree of urbanization. It measures the percentage of land in a region with 1,500 or more addresses (of households

\footnotetext{
${ }^{7}$ The concept of using lagged dependent variables to correct for reversed causality is known in the econometric literature as Granger-causality. See Granger (1969).
}

and firms) per $\mathrm{km}^{2}$. Likewise, the classes 'slightly urbanized' and 'not urbanized' together form an indicator for the degree of rurality, in which all areas are included with 1,000 or less addresses per $\mathrm{km}^{2}$. These variables are measured in the year 2000 .

\section{Results}

5.1 Time structure of the impact of new firms on regional employment growth

We compute the short-, medium- and long-run impact of new firm formation on employment growth using the Almon method as described in Sect. 4.1. We choose to include the start-up rate from the current year as well as lagged start-up rates, up until 8 years. ${ }^{8}$ Furthermore, we compute Almon polynomials of second, third and fourth degree. Considering that our data base contains data for the period 1988-2002 and our choice to include eight lags, implies that we can use 6 years in our estimation sample, hence the sample before removal of outliers consists of 240 observations (as there are 40 regions). Estimation results are in Table 5.

From the left part of the table (unrestricted regression) we see that only the first and the last lag of the start-up rate are significant, illustrating the multicollinearity problems described earlier. ${ }^{9}$ In the second part of the table the results of the Almon lag estimations are presented. Likelihood ratio tests reveal that a polynomial of third-order is statistically optimal. From Table 5 we see that the loglikelihood

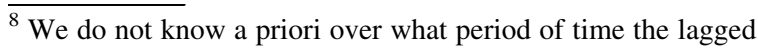
start-up rates still have an impact. We choose a rather long period ( 8 years) in order to allow for the possibility that startup rates of 8 years ago still have an impact on current employment. The choice of 8 years does not imply however that start-ups of 8 years ago actually impact current employment. It is through the Almon lag procedure that we can determine the period (i.e. the maximum lag) for which the lagged start-up rates have an impact.

${ }^{9}$ The joint impact of the current and lagged start-up rates is statistically significant though. The loglikelihood value for a restricted model excluding all start-up rate variables equals -565.4 , while the loglikelihood value for the "unrestricted regression' in Table 5 equals -552.3 . Hence the likelihood ratio test statistic comparing these two models equals 26.2 which is greater than 21.7 , the critical $\chi^{2}$-value at $1 \%$ level with nine degrees of freedom.
} 
Table 5 The impact of lagged start-up rates on regional employment growth ( $t$ to $t-3$ )

\begin{tabular}{|c|c|c|c|c|c|c|}
\hline & \multirow[t]{2}{*}{$\begin{array}{l}\text { Unrestricted } \\
\text { regression }\end{array}$} & \multicolumn{4}{|c|}{$\begin{array}{l}\text { Estimated Almon polynomial of order } n: \beta_{i}=\gamma_{0}+\gamma_{1} i+\cdots+ \\
\gamma_{n} i^{n}(i=\text { lag length in years })\end{array}$} & \multirow{2}{*}{$\begin{array}{l}\text { Restricted start-up } \\
\text { coefficients (lags } \\
\text { in left column) } \\
\text { Third-order }\end{array}$} \\
\hline & & & Second-order & Third-order & Fourth-order & \\
\hline Start-up rate current year $t$ & $\begin{array}{l}0.33 \\
(1.5)\end{array}$ & $\gamma_{0}$ & $\begin{array}{l}-0.14 \\
(1.0)\end{array}$ & $\begin{array}{l}0.12 \\
(0.8)\end{array}$ & $\begin{array}{l}0.21 \\
(1.0)\end{array}$ & 0.124 \\
\hline Start-up rate year $t-1$ & $\begin{array}{l}-0.54 * \\
(2.4)\end{array}$ & $\gamma_{1}$ & $\begin{array}{l}0.13^{*} \\
(2.3)\end{array}$ & $\begin{array}{l}-0.29^{\#} \\
(1.7)\end{array}$ & $\begin{array}{l}-0.55 \\
(1.3)\end{array}$ & -0.068 \\
\hline Start-up rate year $t-2$ & $\begin{array}{l}0.18 \\
(0.8)\end{array}$ & $\gamma_{2}$ & $\begin{array}{l}-0.016^{*} \\
(2.5)\end{array}$ & $\begin{array}{l}0.11 * \\
(2.2)\end{array}$ & $\begin{array}{l}0.26 \\
(1.1)\end{array}$ & -0.101 \\
\hline Start-up rate year $t-3$ & $\begin{array}{l}0.047 \\
(0.2)\end{array}$ & $\gamma_{3}$ & & $\begin{array}{l}-0.010^{*} \\
(2.5)\end{array}$ & $\begin{array}{l}-0.039 \\
(0.9)\end{array}$ & -0.037 \\
\hline Start-up rate year $t-4$ & $\begin{array}{l}-0.062 \\
(0.3)\end{array}$ & $\gamma_{4}$ & & & $\begin{array}{l}0.0018 \\
(0.7)\end{array}$ & 0.065 \\
\hline Start-up rate year $t-5$ & $\begin{array}{l}0.17 \\
(0.9)\end{array}$ & & & & & 0.143 \\
\hline Start-up rate year $t-6$ & $\begin{array}{l}0.11 \\
(0.7)\end{array}$ & & & & & 0.137 \\
\hline Start-up rate year $t-7$ & $\begin{array}{l}0.024 \\
(0.1)\end{array}$ & & & & & -0.015 \\
\hline Start-up rate year $t-8$ & $\begin{array}{l}-0.36^{*} \\
(2.3)\end{array}$ & & & & & -0.371 \\
\hline Wage growth $t-3$ & $\begin{array}{l}0.24 * * \\
(6.1)\end{array}$ & & $\begin{array}{l}0.20 * * \\
(5.7)\end{array}$ & $\begin{array}{l}0.24 * * \\
(6.5)\end{array}$ & $\begin{array}{l}0.24 * * \\
(6.4)\end{array}$ & \\
\hline $\begin{array}{l}\text { Spatial autocorrelation } \\
\text { (residuals in adjacent regions) }\end{array}$ & $\begin{array}{l}0.45^{* *} \\
(2.7)\end{array}$ & & $\begin{array}{l}0.63 * * \\
(4.1)\end{array}$ & $\begin{array}{l}0.56^{* *} \\
(3.8)\end{array}$ & $\begin{array}{l}0.54 * * \\
(3.4)\end{array}$ & \\
\hline$R^{2}$ & 0.702 & & 0.679 & 0.691 & 0.693 & \\
\hline Loglikelihood & -552.3 & & -560.7 & -556.2 & -555.8 & \\
\hline Number of observations & 233 & & 233 & 233 & 233 & \\
\hline
\end{tabular}

Estimated with fixed effects. Absolute heteroskedastic-consistent $t$-values in parentheses. Employment growth, start-up rate and wage growth are all sector adjusted. Employment growth and (lagged) wage growth are measured over periods of 3 years \#Significant at the $10 \%$ level

*Significant at the $5 \%$ level

**Significant at the $1 \%$ level

values for the restricted regressions using second-, third- and fourth-order Almon polynomials are $-560.7,-556.2$ and -555.8 , respectively. Hence, a likelihood ratio test comparing second to third-order polynomial rejects second-order in favour of thirdorder (test statistic 9.0 for a $1 \%$ critical value of 6.64). Similarly, a likelihood ratio test comparing third- to fourth-order does not reject third-order in favour of fourth-order (test statistic 0.8 which is not even significant at $10 \%$ level). The finding that the third-order polynomial is statistically superior is consistent with findings of other studies (Baptista et al. 2007; Fritsch and Mueller 2004, 2007).

For the regression with $n=3$ we see that the linear, quadratic and third degree terms are all significant. Furthermore both the control variables wage growth and spatial autocorrelation are significant (the positive sign pointing at positive interdependency of neighbouring regions) and the $R^{2}$-value is quite high (0.691), indicating a good model fit.

The restricted start-up coefficients resulting from the third-order Almon estimation are in the most right 


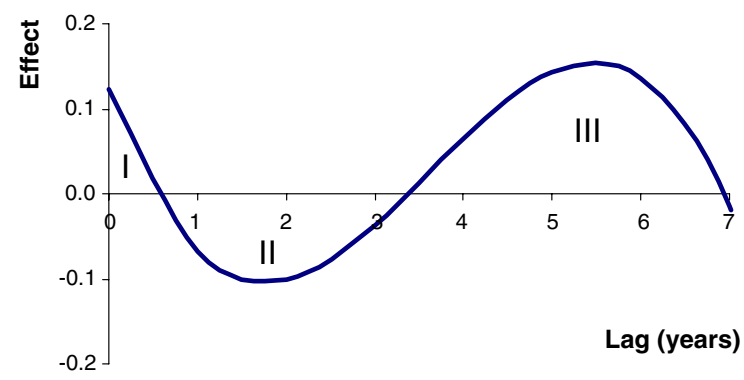

Fig. 1 The estimated lag structure (third-order Almon polynomial)

column of Table 5. This lag structure is presented graphically in Fig. $1 .^{10}$ The graph confirms the pattern described by Fritsch and Mueller (2004). First, there is a period of immediate job creation by the new firms (area I). Next, there is a period of crowding-out of competitors (area II). ${ }^{11}$ Finally, there are positive indirect supply side effects. After some years the intensified competition induced by the new entrants results in a restructuring of the market, which is accompanied by positive effects at the aggregate level. Examples of these types of effects are: more efficient production by incumbents because of the (threat of) increased competition; acceleration of structural change/innovation and an increased variety of products in the market.

In analysing graphics like Fig. 1 two aspects are of major (policy) importance. First, how long does it take before the maximum economic impact of new firm formation is reached? Second, how big is the net employment-effect (in terms of Fig. 1, how big are the areas I, II and III?). The answers to both these questions can be assumed to depend on the quality of the new firms. If the quality of the newcomers is high the net-effect is likely to be positive as the incumbent firms are considerably stimulated to perform better (the threat of the new firms is more severe). They may for instance increase efficiency freeing up resources for growth in other (new) parts of the market (niches). If the new firms are not so competitive the indirect supply side effects are likely to be smaller and the net-effect may well be negative. From

\footnotetext{
${ }^{10}$ The picture for the fourth-order polynomial (not in the paper) looks very similar.

11 Area II also captures employment losses in the nonsurviving new firms.
}

Fig. 1, we see that for our sample of Dutch regions the estimated impact is maximal after 5.5 years. Furthermore, comparing the size of areas I and III on the one hand, and the size of area II on the other, we conclude that for The Netherlands in the period 1988-2002 the net-effect is positive. ${ }^{12}$ Comparing these results with similar studies for Portugal (see Baptista et al. 2007) and Great Britain (and in particular Scotland and Wales, see Mueller et al. 2007), it seems that The Netherlands performs better, both in terms of the time required to reach the maximum economic impact, and in terms of the size of the net-effect. This suggests that the average quality of a new-firm start-up in The Netherlands may be relatively high.

\subsubsection{Interpreting the 'immediate effect'}

In Fig. 1 the area corresponding to the immediate effect (area I) is positive, suggesting that-on average-new firms immediately render positive job creation effects. However, considering the Dutch economy this result is not as straightforward as it may seem at first sight. In particular, relatively many new firms do not hire employees at the start. According to Bangma et al. (2005), on average over the period 1987-2003 each independent new-firm start-up in The Netherlands created 1.5 jobs at the start of the firm, including that of the entrepreneur/business owner. Considering that in our study the employment measure excludes the self-employed, one might expect a negative effect. When a new firm is started by someone who was previously wage-employed, ${ }^{13}$ the number of employees goes down by one, while

\footnotetext{
${ }^{12}$ An alternative method to estimate the net-effect is to add the separate coefficients of the start-up rates. The sum of the separate coefficients from Table 5 (either the sum of the unrestricted or the sum of the restricted coefficients) is negative. However, from Fig. 1 we see that phase III ends after 7 years implying that start-up rates, which are lagged more than 7 years have no impact on current employment. Hence the negative coefficient for the eighth lag should not be counted when computing the net-effect. The negative value of this coefficient is probably due to misspecification of the unrestricted model, i.e. we allow for an impact of 8 years while actually the impact dies out after 7 years. Indeed when we estimate the model allowing for an impact of 7 years only, the sum of the unrestricted coefficients is positive (0.485), consistent with Fig. 1.

${ }^{13}$ In The Netherlands, on average two out of every three startups are started by persons who were previously wageemployed (van Uxem and Bais 1996).
} 
only half a (wage) job is created (excluding the job of the entrepreneur). So, given our employment measure one would expect the immediate effect to be negative.

One possible explanation for the positive immediate effect in Fig. 1 (area I) may be the reversed causality issue discussed earlier. New firms may want to locate in regions with strong economic performance as local demand is likely to be high in such regions. Also, it may be more attractive to start a new firm in a period of high-growth rates compared to a recession period. ${ }^{14}$ Hence the reversed effect is expected to be positive. As the start-up rates of the current year and of the first two lags on the one hand, and the dependent variable employment growth on the other hand, are measured in the same period (see the top and middle line in Fig. 2), the possibility that the immediate effect is overestimated, cannot be ruled out.

This can be explained as follows. As explained earlier, both the (theoretical) immediate employment effect and the reversed effect are expected to be positive. However, because the period in which the immediate employment effect is expected to emerge, overlaps with the period in which a reversed causality effect might take place (this is the period during which the dependent and independent variables overlap, compare the top and middle line in Fig. 2), the direction of causality is hard to disentangle from the regression output. In other words, it is possible that the immediate effect computed on the basis of the regression coefficients, is actually overestimated. If in reality a positive reversed effect exists, then, to some extent, this effect will be picked up by the OLS coefficients, and hence the estimated impact of the start-up rates of the most recent years will be higher than the real (unknown) immediate employment effect.

To test this, we estimated an Almon lag polynomial where the first two lags were excluded, so that only the most recent start-up rate used overlaps with the period of employment growth (compare the top and bottom line in Fig. 2). In this way the chance that a reversed effect is picked up by the regression coefficients is reduced considerably. ${ }^{15}$ Results are

\footnotetext{
$\overline{{ }^{14} \text { Considering }}$ the 'within' estimation context of the current application (see Sect. 4), this latter explanation is actually more valid here. In other words, differences over time are more important than differences between regions.

15 This possibility can never be ruled out completely because of path dependency in the employment growth variable.
}

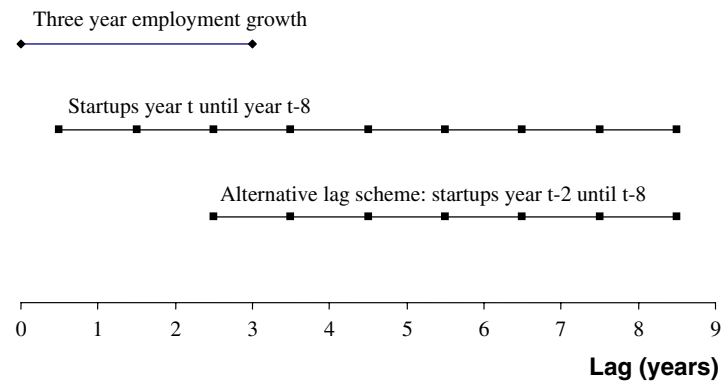

Fig. 2 Different lag schemes start-up rates relative to period of employment growth

displayed in Table 6 and Fig. 3. Remarkably, we no longer find an immediate positive effect of new firms on regional employment. Parameter estimate $\gamma_{0}$ is negative. Even though this estimation is artificial (the impact in the current year and 1 year lagged start-up rate is equal to zero by construction), it does illustrate that in Fig. 1 the immediate effect might be

Table 6 Estimating an alternative Almon polynomial function

Estimated third-order Almon polynomial $\beta_{i}=\gamma_{0}+\gamma_{1}(i-2)+\gamma_{2}(i-2)^{2}+\gamma_{3}(i-2)^{3}$ (i= lag length in years)

$\gamma_{0}$

$-0.239$

$\gamma_{1}$

$0.517^{\#}$

$\gamma_{2}$

$-0.160^{\#}$

$\gamma_{3}$

$0.013 *$

Wage growth

Wage growth

$0.253 * *$

(5.4)

Spatial autocorrelation

$R^{2}$

0.773

Number of observations

155

Estimated with fixed effects. Absolute heteroskedasticconsistent $t$-values in parentheses. Employment growth, startup rate and wage growth are all sector adjusted. Employment growth and (lagged) wage growth are measured over periods of 3 years

\#Significant at the $10 \%$ level

*Significant at the $5 \%$ level

**Significant at the $1 \%$ level 


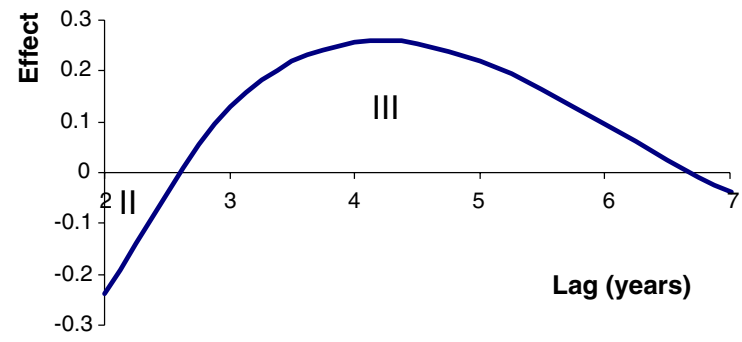

Fig. 3 The estimated lag structure (third-order Almon polynomial), excluding the first two periods

overestimated due to reversed causality. When the first 2 years are removed the positive area is replaced by a negative area. Also note that in both Figs. 1 and 3 the later positive effect ends after about 7 years. It is likely that the early negative effect in Fig. 3 corresponds to area II in Fig. 1 and the later positive effect to area III in Fig. 1. From this exercise we conclude that the direct immediate job-creating impact of new firms is overestimated in Fig. 1.

\subsection{Does the impact of new firms on regional development differ by sector?}

In this section, we investigate whether the relation between regional start-up rates and employment growth differs across sectors of economic activity. ${ }^{16}$ Considering the focus on cross-regional differences, and to avoid a downward bias in the standard error, we use non-overlapping 3-year periods in each sample (as employment change is measured over 3 years), resulting in four time observations (1994, 1996, 1999 and 2002). As there are 40 regions this results for each sector in a sample of 160 observations, before removal of outliers. ${ }^{17}$

Results of the sector-specific analyses are presented in Table 7. The result that stands out is that the impact of new firm formation is by far the largest for manufacturing. Even though both average employment growth and the average start-up rate are the lowest of all sectors (see Table 2), those regions,

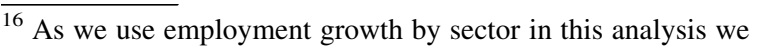
are not able to account for the effects that the start-up might have on the intersectoral division of labour.

17 Note that the non-significance of the Jarque Bera (JB) statistics indicates the cleaned samples residuals are normally distributed.
}

which have relatively high start-up rates in manufacturing benefit in terms of employment. This may be related to the greater importance of innovation in manufacturing compared to, for instance, services. Innovation in service firms has a different character than in manufacturing. In particular, innovations in service industries are often non-technological and they mostly involve small and incremental changes in processes and procedures (de Jong et al. 2003, p. 16). To the contrary, innovations in manufacturing tend to require more $R \& D$ and are often more radical in nature. In modern entrepreneurial economies radical innovation is more conducive to economic growth than incremental innovation. This is because industry life-cycles are shorter and hence, at a given point in time, more (niche) markets are in an early stage of the life cycle where $R \& D$ is highly productive and the costs of radical innovation tend to be relatively low (Audretsch and Thurik 2001). Hence, a lack of entrepreneurship in manufacturing industries may be particularly damaging to economic performance, as it may imply a lack of incentives to create (radical) innovations.

Given the above background it may be the case that a highly skilled entrepreneurial individual chooses to set up a business in manufacturing instead of a business in the services sector. Starting a business in manufacturing may be more challenging to such an individual because higher technical skills are required in this sector. If the higher skilled entrepreneurs choose to start businesses in manufacturing instead of in other sectors, this may cause the average quality of a start-up in manufacturing to be higher, which, in turn, causes the employment impact of a new firm to be higher. In other words, a selection effect may be at play. However, a different explanation for the large effect in manufacturing is related to the bigger average firm size compared to other sectors (minimum efficient scale is higher). It is likely that on average start-up size in manufacturing is also bigger compared to other sectors, implying that the direct employment effect may be relatively pronounced. In other words, market structure effects also contribute to the differences found in Table 7 . We note that by the current empirical exercise we are only able to establish the common effect, in other words we are not able to distinguish empirically between the selection effect and the market structure effect. 
Table 7 Determinants of regional employment growth by sector

\begin{tabular}{llllll}
\hline & Manufacturing & Construction & Trade & Transport and communication & Services \\
\hline Constant & $-8.70^{* *}$ & -2.99 & 0.94 & 0.16 & $5.28^{* *}$ \\
& $(7.06)$ & $(1.54)$ & $(0.54)$ & $(0.06)$ & $(2.82)$ \\
Start-up rate & $1.28^{* *}$ & $0.39^{* *}$ & $0.14^{*}$ & $0.39^{*}$ & $0.34^{* *}$ \\
& $(5.32)$ & $(3.24)$ & $(2.35)$ & $(2.18)$ & $(4.14)$ \\
Population density & $-0.003^{* *}$ & -0.003 & $-0.001 * *$ & 0.002 & -0.0009 \\
& $(4.47)$ & $(1.88)$ & $(3.19)$ & $(1.05)$ & $(1.71)$ \\
Wage growth & $0.13 * *$ & 0.12 & $0.21 * *$ & -0.071 & $0.18^{* *}$ \\
& $(2.87)$ & $(1.93)$ & $(3.90)$ & $(0.90)$ & $(3.36)$ \\
Lagged growth & -0.071 & -0.079 & 0.003 & -0.031 & $-0.13 *$ \\
& $(1.25)$ & $(0.90)$ & $(0.05)$ & $(0.38)$ & $(2.12)$ \\
Spatial autocorrelation & $0.89 * *$ & 0.20 & $0.70 * *$ & $0.40^{* *}$ & $0.90^{* *}$ \\
& $(8.84)$ & $(0.94)$ & $(4.40)$ & $(2.80)$ & $(11.02)$ \\
Adjusted $R^{2}$ & 0.512 & 0.117 & 0.320 & 0.055 & 0.548 \\
JB test [ $p$-value] & {$[0.409]$} & {$[0.794]$} & {$[0.365]$} & {$[0.957]$} & {$[0.972]$} \\
Number of observations & 157 & 158 & 155 & 154 & 157 \\
\hline
\end{tabular}

Absolute heteroskedastic-consistent $t$-values in parentheses

*Significant at the $5 \%$ level

**Significant at the $1 \%$ level

5.3 Does the impact of new firms on regional development differ by degree of urbanization?

In this section, we investigate whether the relation between regional start-up rates and employment growth differs across different parts of the country, and in particular, whether the degree of urbanization plays a role. It is imaginable that the effect of startups in urbanized regions is stronger, for instance because of the agglomeration effects discussed in Sect. 2.1. In addition, human capital levels in peripheral areas may on average be lower compared to urbanized regions, for instance because the highly educated move away to the bigger cities where employment opportunities are better. This, in turn, may cause the average start-up in a peripheral area to be of a lower quality compared to the average start-up in an urbanized region (selection effect). Mueller et al. (2007) provide empirical evidence showing that the employment impact of new firms is smaller in Scotland and Wales compared to regions in England. These authors suggest that human capital levels of business founders in the peripheral areas Scotland and Wales are on average lower than human capital levels of business founders in England.
We investigate whether the impact of start-ups differs with the degree of urbanization or rurality of a COROP region. For this purpose, we created interaction terms of the start-up rate multiplied by the degree of urbanization or the degree of rurality as defined in Sect. 4.2. ${ }^{18} \mathrm{We}$ pool data for four time periods, five sectors and 40 regions resulting in 800 observations before cleaning of outliers. Results are in Table 8 . We estimate two slightly different models. First, we examine whether the impact of new firms increases with the degree of urbanization (Model I). Table 8 suggests that this might be the case as the interaction term is positive. The effect is not significant though. Second, we examine whether the impact decreases with the degree of rurality (Model II). Table 8 suggests that this is indeed the case. The interaction effect in Model II is significantly negative. The same number of new firms create less jobs in a rural area compared to a non-rural area.

\footnotetext{
${ }^{18} \mathrm{We}$ also include the degree of urbanization (rurality) as a separate variable in the model, in order to safeguard straightforward interpretation of the coefficient of the interaction term. As the correlation between the degree of urbanization and population density is very high (0.9), the latter variable is removed from this model specification.
} 
Table 8 Determinants of regional employment growth by degree of urbanization/rurality

\begin{tabular}{lll}
\hline & Model I & Model II \\
\hline Constant & $-6.0^{* *}$ & $-10.3^{* *}$ \\
& $(7.0)$ & $(8.9)$ \\
Start-up rate & $0.30^{* *}$ & $0.49^{* *}$ \\
& $(4.6)$ & $(5.9)$ \\
Degree of urbanization & $-5.3^{* *}$ & \\
& $(2.8)$ & \\
Start-up rate, interaction term & 0.19 & \\
$\quad$ degree of urbanization & $(1.5)$ & \\
Degree of rurality & & $5.3 * *$ \\
Start-up rate, interaction term & & $(2.8)$ \\
degree of rurality & & $-0.26^{*}$ \\
Wage growth & & $(2.0)$ \\
Lagged growth & $0.14^{* *}$ & $0.14 * *$ \\
Spatial autocorrelation & $(5.4)$ & $(5.4)$ \\
Adjusted $R^{2}$ & -0.047 & -0.042 \\
Number of observations & $(1.3)$ & $(1.2)$ \\
\hline & $0.69^{* *}$ & $0.69^{* *}$ \\
Absalue] & $(11.5)$ & $(11.5)$ \\
& 0.506 & 0.504 \\
& {$[0.052]$} & {$[0.049]$} \\
& 777 & 777 \\
\hline
\end{tabular}

Absolute heteroskedastic-consistent $t$-values in parentheses. Sector dummies not reported

*Significant at the $5 \%$ level

**Significant at the $1 \%$ level

The result from Table 8 might be explained by agglomeration effects such as a higher degree of knowledge spillovers in more dense regions. This explanation might interact with the observation that new firms in rural areas are often of a different nature compared to new firms in urbanized regions (selection effect). Using the same CBS data base on the degree of urbanization, Hessels et al. (2005) found that for The Netherlands the Total Entrepreneurial Activity rate (TEA) as measured by the Global Entrepreneurship Monitor, is highest for regions scoring high in the extreme classes 'very urbanized' and 'not urbanized' (i.e. rural), compared to the middle three levels of urbanization. In highly urbanized regions high start-up rates occur due to a highpopulation density. The attitude towards entrepreneurship is positive and business start-ups are services related. In rural regions the high start-up rates are related to a smaller average firm size and the fact that there is a minimal level of shops and stores needed to sustain small village communities. Hence entrepreneurship in rural areas may be more of a subsistence nature. Similar to Sect. 5.2, we note that by the current empirical exercise we are only able to establish the common effect, in other words we are not able to distinguish empirically between the selection effect and the agglomeration effect.

We find the different impact of new-firm start-ups for urban and rural regions in Table 8 quite intriguing. Therefore we also want to investigate a different aspect: are the time patterns of the impact different? We use the Almon lag methodology introduced earlier in the paper. In particular we split the 233 observations sample used in Table 5 in urban and rural regions. For urban regions we use the highly urbanized 'Randstad' area in the West of The Netherlands. These are the COROP regions in the provinces Utrecht, North-Holland and South-Holland. The remaining COROP regions are categorized as 'rural'. To illustrate the difference between the two samples, the average degree of urbanization (rurality), as defined in Sect. 4.2, is $56 \%$ (26\%) for the Randstad sample, and $20 \%(62 \%)$ for the 'rural' sample. Note that the remaining percentage $(18 \%$, for both samples) refers to the category 'moderately urbanized' (see Sect. 4.2).

Estimation results for the third-order polynomial are presented in Table 9, while the corresponding time patterns of the impact of new firms are depicted in Fig. 4. We see that the impact of new-firm formation is larger in the urban regions compared to the rural regions, consistent with our earlier findings in Table 8. What is striking though is that the impact for the urban sample does not become negative, and that for the rural regions there is no positive direct effect. As suggested earlier, both agglomeration effects and selection effects may explain these differences. However, more research is needed to fully understand the different patterns shown in Fig. 4.

Although more research is needed in this area we may conclude from the above exercises that the location of a new firm is important. This is in line with findings of Hoogstra and van Dijk (2004). They address the question to what extent the location of a firm can be regarded as having an influence on employment growth of a firm. Using an econometric 
Table 9 Estimating separate Almon polynomial functions for urban and rural regions

Estimated third-order Almon polynomial

$\beta_{i}=\gamma_{0}+\gamma_{1} i+\gamma_{2} i^{2}+\gamma_{3} i^{3}(i=$ lag length in years $)$

\begin{tabular}{lll}
\hline & Urban regions: 'Randstad' & Rural regions \\
\hline$\gamma_{0}$ & $0.72 * *$ & -0.057 \\
& $(2.7)$ & $(0.3)$ \\
$\gamma_{1}$ & $-0.54^{*}$ & -0.20 \\
& $(2.1)$ & $(0.9)$ \\
$\gamma_{2}$ & $0.17 *$ & 0.086 \\
& $(2.4)$ & $(1.2)$ \\
$\gamma_{3}$ & $-0.014 * *$ & -0.0083 \\
& $(2.7)$ & $(1.5)$ \\
Wage growth & $0.30^{* *}$ & $0.21^{* *}$ \\
& $(6.5)$ & $(3.8)$ \\
Spatial & $0.83^{* *}$ & $0.45^{*}$ \\
autocorrelation & $(4.1)$ & $(2.2)$ \\
$R^{2}$ & 0.779 & 0.682 \\
Number of & 84 & 149 \\
observations & & \\
\hline
\end{tabular}

Estimated with fixed effects. Absolute heteroskedasticconsistent $t$-values in parentheses. Employment growth, startup rate and wage growth are all sector adjusted. Employment growth and (lagged) wage growth are measured over periods of 3 years. The 'Randstad' sample is formed by the COROP regions of the provinces Utrecht, North-Holland and SouthHolland

*Significant at the $5 \%$ level

**Significant at the $1 \%$ level

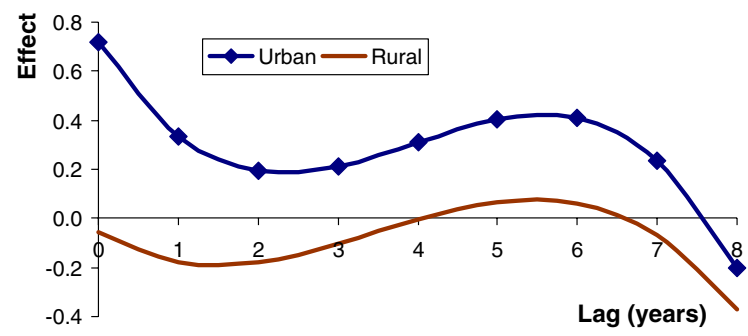

Fig. 4 The estimated lag structure (third-order Almon polynomial), urban versus rural areas

model based on a data set of circa 35,000 establishments in the northern provinces of The Netherlands, they find that 'location matters'. In particular the authors find that both belonging to a spatial cluster of similar firms and a great diversity of economic activities in the area a firm is located enhances employment growth of that firm. Our results are also in line with the study of Brakman et al. (2005), described in Sect. 2.1, who find empirical support for an 'agglomeration equilibrium' to exist.

\section{Discussion}

In this paper, the relationship between new firm formation and regional employment change has been examined. Using a new regional data base for the period 1988-2002, we examine the time lags involved in the relationship. We also investigate whether the relationship differs by sector and by degree of urbanization. We find that the maximum effect of new businesses on regional development is reached after about 6 years. Our results also suggest that the overall employment impact of new-firm startups is positive but that the immediate employment effects may be small in The Netherlands. Furthermore, we find that the employment impact of new firms is strongest for manufacturing and that the employment impact of new firms is stronger in areas with a higher degree of urbanization.

Our research has several policy implications related to the short and long-run effects of new firm formation. First, concerning short-term effects, policy makers are often inclined to stimulate business creation on the ground that new firms immediately create jobs. Our exercises suggest however that the immediate employment effect may actually be small in The Netherlands. Second, concerning long-run effects, policy makers are often inclined to neglect these, or at least to put less emphasis on these effects. However, as the longer-term effects may well be substantial, it is of vital importance to take these into account when considering regional growth policies (Martí 2004; Hoogstra and van Dijk 2004). The Almon lag model used in the present study is able to take the short as well as the long-run effects into account. We find that the maximum impact is reached after about 6 years and that the net-employment effect of start-ups is positive. Comparing these results with those obtained for other countries (in particular Portugal, Scotland and Wales), we see that the maximum economic impact is reached faster, and that the net employment-effect is larger. This tentatively suggests that the average quality of a new-firm start-up in The Netherlands may be relatively high. 
However, this should not be taken as an encouragement to implement policies designed to maximize the number of new-firm start-ups, particularly in peripheral regions. The net-employment effect is dependent on the quality of the new firms. Once business creation in peripheral areas is subsidized this may attract entrepreneurs with lower levels of human capital who contribute negatively to regional development. Research for Great Britain by Mueller et al. (2007) provides some intuition for this hypothesis. Using a similar Almon lag approach they show that the net employment-effect of new firms is smaller for regions in Scotland and Wales compared to English regions. In a British context Scotland and Wales may be considered peripheral lagging regions with relatively many (often subsidized) start-ups in easy to enter, non-innovative sectors. From a policy perspective the British results suggest that subsidizing entry may not be productive if the subsidized entrants are in easy to enter, non-innovative sectors such as vehicle-repairing and window cleaning (van Stel and Storey 2004).

The conclusion that stimulating business creation in peripheral areas may be inefficient is also in line with the study by Brakman et al. (2005), described in Sect. 2.1. By estimating econometric models derived from the New Economic Geography, they find empirical support for an 'agglomeration equilibrium' to exist, suggesting that for their European data set the agglomeration advantages (such as higher levels of knowledge spillovers) outweigh the disadvantages (such as traffic congestion). This would imply that regional disparities are persistent and hence difficult to counter with regional policy. The authors therefore conclude that attracting economic activity to the periphery through subsidies does not make sense, as this economic activity will in the long run be pulled to the core because of agglomeration advantages. The periphery lacks the critical economic mass to hold on to mobile firms. While the results of Brakman et al. (2005) are valid in a general European context, results in the present study suggest that structural differences between regions matter within The Netherlands as well. We find the employment effect of start-ups in rural areas to be smaller compared to the effect in urban areas. It is conceivable that many of the more mobile startups in the periphery who find that they are less effective because of their location will relocate in the core. ${ }^{19}$ Therefore it is far from obvious that potential regional policies designed to maximize the number of start-ups in peripheral areas will have the desired effects on the regional economy.

Although the prior comments are caveats against generic quantity-based business stimulation policies, this is not to say that any stimulation policy would be futile. Instead, when considering business stimulation policies, both the quantity and the quality of the newfirm start-ups should be taken into account.

Acknowledgements We are grateful to Michael Fritsch, Jolanda Hessels, Niels Bosma, Gerrit de Wit, two anonymous referees, and participants at the workshop on 'The Effects of New Businesses on Economic Development in the Short, Medium and Long Run' (Jena, July 11-12, 2005), for providing us with helpful comments and suggestions. The paper has been written in the framework of the research programme SCALES carried out by EIM and financed by the Dutch Ministry of Economic Affairs. Besides EIM and Cranfield University, André van Stel is also affiliated with Erasmus University Rotterdam (Rotterdam, The Netherlands), and Max Planck Institute of Economics (Jena, Germany).

\section{References}

Agrawal, A. (2002). Innovation, growth theory and the role of knowledge spillovers. Innovation Analysis Bulletin, 4(3), 3-6.

Ashcroft, B., Love, J., \& Malloy, E. (1991). New firm formation in the British counties with special reference to Scotland. Regional Studies, 25, 395-409.

Audretsch, D. (1998). Agglomeration and the location of innovative activity. Oxford Review of Economic Policy, 14, 18-29.

Audretsch, D., \& Fritsch, M. (1994). On the measurement of entry rates. Empirica, 21, 105-113.

Audretsch, D., \& Fritsch, M. (2002). Growth regimes over time and space. Regional Studies, 36, 113-124.

Audretsch, D., \& Thurik, R. (2001). What is new about the new economy: Sources of growth in the managed and entrepreneurial economies. Industrial and Corporate Change, 10, 267-315.

Autant-Bernard, C. (2001). The geography of knowledge spillovers and technological proximity. Economics of Innovation and New Technology, 10(4), 237-254.

Bangma, K., Gibcus, P., \& van Eck van der Sluijs, L. (2005). Bedrijvendynamiek en Werkgelegenheid Periode 19872004 (in Dutch), EIM Publieksrapportage A200415. Zoetermeer: EIM.

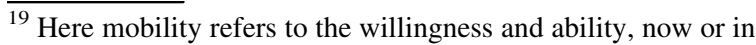
the future, to move the firm if required by (economic) circumstances. Furthermore, as mentioned in Sect. 5.3, whether agglomeration effects or selection effects dominate, this is still an open question.
} 
Baptista, R., Escária, V., \& Madruga, P. (2007). Entrepreneurship, regional development and job creation: the case of Portugal. Small Business Economics (present issue).

Birch, D. (1987). Job creation in America: How our Smallest companies put the most people to work. New York: The Free Press.

Bosma, N., \& Nieuwenhuijsen, H. (2002). Turbulence and productivity; an analysis of 40 Dutch regions in the period 1988-1996, EIM scales paper N200205. Zoetermeer: EIM.

Brakman, S., Garretsen, H., Gorter, J., van der Horst, A., \& Schramm, M. (2005). New economic geography, empirics, and regional policy, $C P B$ special publications, no. 56. The Hague: CPB.

Broersma, L., \& Gautier, P. (1997). Job creation and job destruction by small firms: An empirical investigation for the Dutch manufacturing sector. Small Business Economics, 9, 211-224.

Caniëls, M. (2000). Knowledge spillovers and economic growth. Regional growth differentials across Europe. Cheltenham: Edward Elgar.

Davis, S., Haltiwanger, J., \& Schuh, S. (1996). Small business and job creation; dissecting the myth and reassessing the facts. Small Business Economics, 8, 297-315.

EIM (1994). Kleinschalig ondernemen 1994, deel 2: regionaaleconomische dynamiek en werkgelegenheidscreatie (in Dutch). Zoetermeer: EIM.

Fritsch, M. (2007). How does new business formation affect regional development? Introduction to the special issue. Small Business Economics (present issue).

Fritsch, M., \& Mueller, P. (2004). Effects of new business formation on regional development over time. Regional Studies, 38, 961-975.

Fritsch, M., \& Mueller, P. (2007). The effect of new business formation on regional development over time: The case of Germany. Small Business Economics (present issue).

Fujita, M., Krugman, P., \& Venables, A. (1999). The spatial economy: Cities, regions, and international trade. Cambridge, MA: MIT Press.

Fujita, M., \& Thisse, J. -F. (2002). Economics of agglomeration: Cities, industrial location, and regional growth. Cambridge, UK: Cambridge University Press.

Garofoli, G. (1994). New firm formation and regional development: The case of Italy. Regional Studies, 28, 381-393.

Granger, C. (1969). Investigating causal relations by econometric models and cross-spectral methods. Econometrica, 37, 424-438.

Hessels, J., Bosma, N., \& Wennekers, S. (2005). Nieuw ondernemerschap in herstel; global entrepreneurship monitor 2004 Nederland (in Dutch), EIM publieksrapportage A200502. Zoetermeer: EIM.
Hoogstra, G., \& van Dijk, J. (2004). Explaining firm employment growth: Does location matter? Small Business Economics, 22, 179-192.

de Jong, J., Bruins, A., Dolfsma, W., \& Meijaard, J. (2003). Innovation in service firms explored: What, how and why? EIM Strategic Study B200205. Zoetermeer: EIM.

de Kok, J., de Wit, G., \& Suddle, K. (2006). SMEs as job engine of the Dutch private economy; a size class decomposition of employment changes for different sectors of the Dutch economy, EIM research report H200601. Zoetermeer: EIM.

Martí, F. P. (2004). Promoting the entry of new firms. Small Business Economics, 22, 209-221.

Meijaard, J. (2001). Making sense of the new economy. $E$ Commerce Research Forum, 2(5), 27-57 (Massachusetts Institute of Technology).

Mueller, P., van Stel, A., \& Storey, D. (2007). The effects of new firm formation on regional development over time: The case of Great Britain. Small Business Economics (present issue).

Picot, G., \& Dupuy, R. (1998). Job creation by company size class: The magnitude, concentration and persistence of job gains and losses in Canada. Small Business Economics, 10, 117-139.

Rees, H., \& Shah, A. (1986). An empirical analysis of selfemployment in the UK. Journal of Applied Econometrics, 1, 95-108.

van Stel, A., \& Nieuwenhuijsen, H. (2004). Knowledge spillovers and economic growth: An analysis using data of Dutch regions in the period 1987-1995. Regional Studies, 38, 393-407.

van Stel, A., \& Storey, D. (2004). The link between firm Births and job creation: Is there a Upas tree effect? Regional Studies, 38, 893-909.

Stewart, J. (1991). Econometrics. New York: Philip Allan.

van Uxem, F., \& Bais, H. (1996). Het Starten van een Eigen Bedrijf; Ervaringen van 2000 Starters (in Dutch). Zoetermeer: EIM.

Verhoeven, W. (2004). Firm dynamics and labour productivity. In G. Gelauff, L. Klomp, S. Raes, \& T. Roelandt (Eds.), Fostering productivity: Patterns, determinants and policy implications (pp. 213-241). Amsterdam: Elsevier B.V.

Verhoeven, W., Gibcus, P., \& de Jong-'t Hart, P. (2005). Bedrijvendynamiek in Nederland: Goed of Slecht? (in Dutch). Zoetermeer: EIM.

Werker, C., \& Athreye, S. (2004). Marshall's disciples: Knowledge and innovation driving regional economic development and growth. Journal of Evolutionary Economics, 14, 505-523. 